\section{Specific cytotoxic T cells eliminate cells producing neutralizing antibodies}

\author{
Oliver Planz, Peter Seiler, Hans Hengartner \\ \& Rolf M. Zinkernagel
}

Institute for Experimental Immunology, Department of Pathology, University of Zürich, Schmelzbergstrasse 12, CH-8091 Zürich, Switzerland

IN medically important infections with cytopathic viruses, neutralizing antibodies are generated within 6-14 days. In contrast, such protective antibodies appear late (50-150 days) after infection with immunodeficiency virus (HIV) and hepatitis B virus (HBV) in humans, or lymphocytic choriomeningitis virus (LCMV) in mice ${ }^{1-6}$. However, during these infections, nonneutralizing antibodies appear much earlier ${ }^{2,6,7}$. It has been proposed that $\mathbf{T}$ cells suppress antibody responses generally and against viruses in vitro ${ }^{6,8-10}$. Here we show that the suppression of neutralizing-antibody responses in LCMV infections in mice is due to selective infection of neutralizing-antibodyproducing $B$ cells by this non-cytopathic virus, and their subsequent destruction by virus-specific cytotoxic $T$ cells. Such specific B-cell elimination that leads to a delay in neutralizingantibody production could help to establish persistent virus infections by non-cytopathic viruses.

LCMV is a non-cytopathic virus with a wide tropism in its natural murine host, which includes antigen-presenting cells like macrophages and dendritic cells and most other somatic cells. Recovery from primary infection depends on $\mathrm{CD}^{+} \mathrm{T}$ cells and perforin and protection against reinfection is mediated by $C D 8^{+} \mathrm{T}$ cells and by neutralizing antibodies ${ }^{5,6,11,12}$. LCMV infection leads to immunosuppression due to immunopathological destruction of antigen-presenting cells by virus-specific $\mathrm{CD}^{+} \mathrm{T}$ cells ${ }^{13-15}$. Although neutralizing-antibody responses directed against the LCMV surface glycoprotein (GP) are suppressed, non-neutralizing antibody responses specific for the nucleoprotein (NP) of LCMV are usually unimpaired ${ }^{6}$.

To explore the basis of this selective suppression, we tested whether B cells producing LCMV-neutralizing antibodies were infected preferentially by the virus and were therefore susceptible to lysis by LCMV-specific cytotoxic T cells. Neutralizing antibody titres are not-or are only rarely-measurable after infection with a low dose $\left(10^{2}\right.$ plaque-forming units (PFU)) of LCMV isolate WE (LCMV-WE) for more than 100 days after infection, but are detectable after day 50 in mice infected with a high dose $\left(10^{6} \mathrm{PFU}\right)$ of LCMV-WE (Fig. $\left.1 a, b\right)$. When mice were treated with an anti-CD8-specific T-cell-depleting monoclonal antibody, neutralizing anti-LCMV antibodies were detected earlier (by day 25) after low- and high-dose LCMV infection (Fig. 1c, and data not shown $)^{6}$. In contrast, non-neutralizing antibodies specific for the protein of viral NP appeared early (by $6-8$ days after infection) and kinetics were comparable for normal and $\mathrm{CD}^{+} \mathrm{T}$-celldepleted mice (Fig. 1 $a-c$, and data not shown).

To investigate further the humoral immune response against LCMV at a single-cell level ex vivo, hybridomas were generated by fusing spleen cells of either normal or $\mathrm{CD} 8^{+} \mathrm{T}$-cell-depleted mice on days 2, 4, 6, 10 and 25 after infection with LCMV-WE. Although neutralizing antibodies were not detectable in the serum, we were able to generate hybridomas secreting NP-specific antibodies detected by an NP-specific enzyme-linked immunosorbent assay (ELISA) ${ }^{6}$, but also neutralizing-antibody-producing hybridomas on day 4 after infection of both normal and $\mathrm{CD}^{+} \mathrm{T}$ cell-depleted mice (Table 1, boxes). The percentage of hybridomas producing neutralizing antibodies remained consistently high at $12-16 \%$ of all hybridomas in fusions from spleen cells of $\mathrm{CD}^{+} \mathrm{T}$-cell-depleted mice. But in normal mice the percentage of

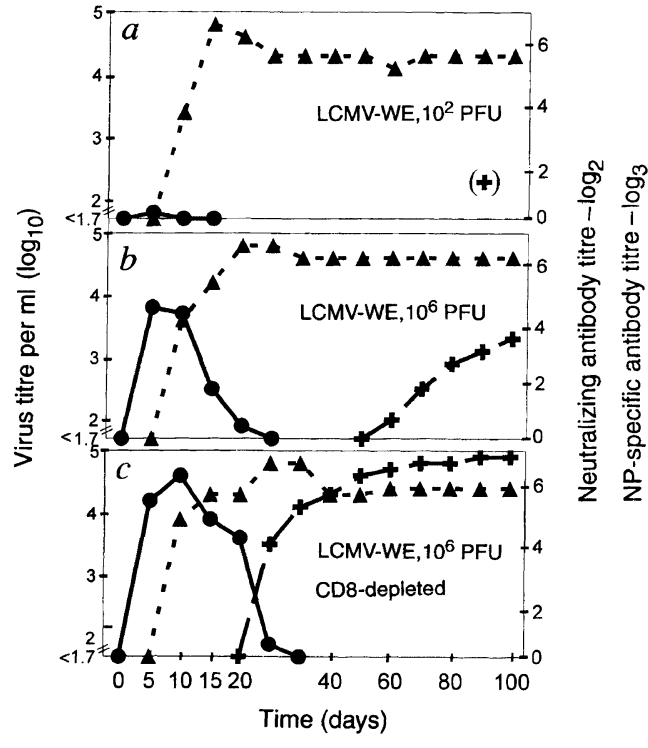

FIG. 1 Kinetics of neutralizing and non-neutralizing antibody responses to LCMV. a, BALB/c mice were infected i.v. with $10^{2}$ PFU of LCMV-WE. Virus titre (O) in the blood of these mice is usually not detectable. Nucleoproteinspecific antibodies $(\boldsymbol{\Lambda})$ appear between days 6 and 8 after infection and stay at a constant level during the whole observation period; the cross in parentheses indicates that only $20 \%$ of BALB/C mice infected with $10^{2}$ PFU LCMV-WE developed measurable neutralizing antibodies within $100 \mathrm{~d}$ of infection. $b, \mathrm{BALB} / \mathrm{c}$ mice infected i.v. with $10^{6} \mathrm{PFU}$ of LCMV-WE eliminated virus (O) from the blood by days 15-25 after infection. The nucleoprotein-specific antibody titre $(\boldsymbol{\Delta})$ was comparable to that after lowdose $\left(10^{2} \mathrm{PFU}\right)$ LCMV infection. Neutralizing antibodies (crosses) were found by around day 60 and later after infection. $c, B A L B / c$ mice were treated with rat anti-CD8 specific mAb (YTS 169.4) 3 and 1 day before LCMV-WE infection ${ }^{19}$. Mice were infected i.v. with $10^{6}$ PFU. LCMV-WE titres (O) in the blood were increased compared with infected but otherwise untreated mice (see $b$ ). Kinetics of nucleoprotein-specific antibodies $(\boldsymbol{\Delta})$ were comparable to those in infected mice from the other groups ( $a$ and $b$ ). Neutralizing antibodies (crosses) were found between days 20 and 25 after infection. Similar results were obtained in CD8-depleted mice after lowdose LCMV infection. All experiments shown used BALB/c mice, but similar results were obtained with $\mathrm{C} 57 \mathrm{BL} / 6$ mice (not shown). All values for viral titres (O) are means of values from 6-8 individual mice; s.e.m. values of viral titres were all $<0.40$; s.e.m.s for neutralizing antibody titres were $<0.66$ and NP-ELISA titres were $<0.15$.

METHODS. Anti-LCMV-NP-titres were measured by ELISA and neutralizing antibody titres by a neutralization assay as described ${ }^{6}$. The neutralizing titre was measured as $-\log _{2}$, starting with a $1: 20$ dilution of serum and was defined as the dilution causing half-maximal reduction of plaques of LCMV with the same amount of virus incubated with control serum. NP-ELISA titres were measured as $-\log _{3}$, starting with a $1: 40$ dilution, and were defined by the dilution causing half-maximal colour reaction.

hybridomas producing neutralizing antibodies dropped markedly after day 4, and only one such hybridoma was isolated between days 10 and 25 after infection (Table 1 , boxes).

Unexpectedly, we found that many hybridoma supernatants contained infectious LCMV. Further analysis showed that only those hybridoma supernatants that contained neutralizing antibodies were LCMV-positive. To eliminate infectious LCMV, supernatants were inactivated with ultraviolet light or treated

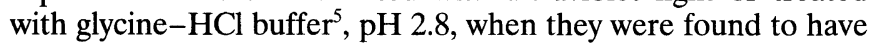
potent neutralizing activity. In contrast, almost no supernatants with NP-specific antibodies contained infectious virus. As shown in Table 1, almost all (51/59) of the neutralizing-antibodyproducing hybridomas, but very few $(2 / 107)$ of the NP-specific hybridomas, were infected with LCMV.

Analysis of LCMV-infected virus-neutralizing antibody-secreting hybridomas showed that some expressed the LCMV-GP on the cell surface homogeneously, whereas others gave heterogeneous 


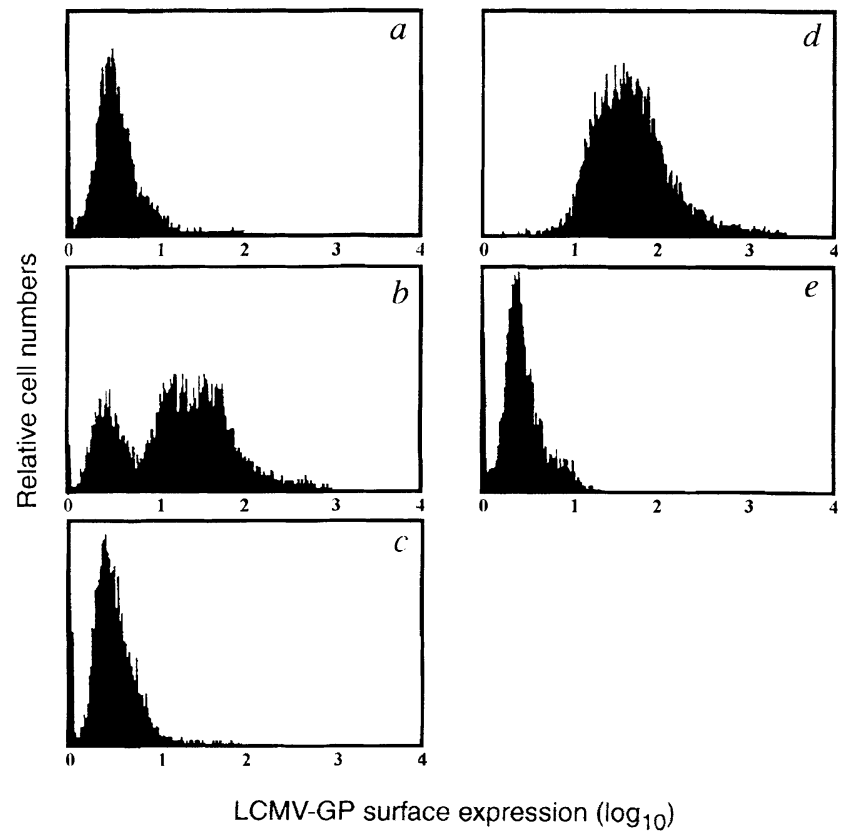

staining (Fig. 2). After 3 subclonings, at 0.3 cells per well without feeder cells to avoid reinfection, all LCMV-infected clones produced neutralizing antibodies, whereas uninfected clones either did not secrete antibodies or secreted antibodies that did not neutralize LCMV (Fig. 2). It should have been possible ${ }^{5}$ to find LCMV-negative clones secreting neutralizing antibodies that had lost the virus during subcloning; but this was not found after 1-3 rounds of subcloning. The homogeneous hybridoma cultures remained stably infected for up to six months, that is, for as long as they were tested. However, by repetitive subclonings at 0.3 to 0.1 cells per well without feeder cells, rare hybridomas free of virus were isolated (Fig. 2). These virus-free subcloned produced 2-3 times more neutralizing activity than infected ones. Neutralizing activity, expressed as standard neutralizing titres of our monoclonal antibodies, were in the range of $1: 2-1: 8$ neutralizing titres at $1 \mu \mathrm{g} \mathrm{ml}^{-1}$ (comparable to the standard neutralizing monoclonal antibody KL25 with a titre of $1: 4.8$ at $1 \mu \mathrm{g} \mathrm{ml}^{-1}$; ref. 16).

We then investigated whether the neutralizing-antibody-secreting cells were infected in the host or during fusion with the myeloma cells. The results showed that: (1) it was unlikely that LCMV infected hybridomas during the fusion process because LCMVNP-specific hybridomas from the same fusion were not infected; (2) hybridomas specific for a variety of third-party antigens, including LCMV-NP or the myeloma cell line P3X63Ag8, could not be infected with LCMV, either in vitro or in vivo in LCMV carrier mice (results not shown); also, LCMV-neutralizing-antibody-producing hybridomas rendered virus-free by subcloning could not be infected (6 of 6 tested; see example in Fig. $3 c$ ), probably because of the general lack of membrane-anchored surface immunoglobulin and the resistance to LCMV infection seen for all hybridomas; (3) infected third-party-antigen- or NPspecific hybridomas were not obtained under conditions in which LCMV $\left(5 \times 10^{8}\right.$ PFU in $\left.10 \mu \mathrm{l}\right)$ was added directly to the cell pellet before fusion (data not shown), so infection of B cells secreting LCMV-neutralizing antibodies must have occurred before fusion.

Taken together, our data indicate that LCMV-neutralizing, membrane-bound immunoglobulin on B cells serves as a specific virus receptor for infection of $B$ cells with LCMV. Because LCMV-NP is not exposed on the virus surface, NP-specific B cells cannot take up infectious LCMV particles, but can only take up and process cell or virus fragments containing nucleoprotein.

Viral infection and the expression of major histocompatibility
FIG. 2 Expression of LCMV-specific antigen on neutralizing-antibodyproducing hybridomas was tested by flow cytometric analysis. One example of 15 tested and subcloned hybridomas is shown; 9 of 15 gave a homogeneous staining pattern. The hybridoma shown is representative of 6 out of the 15 hybridomas that initially gave heterogeneous LCMV-GP staining. After one round of subcloning, we found homogeneously infected hybridomas producing neutralizing antibodies, whereas hybridoma cultures that stained negative for LCMV-GP did not produce neutralizing antibodies. a, Second-antibody control staining of an LCMV-infected hybridoma (4/4F7) with FITC-labelled goat anti-rabbit (IgG) antibody. $b$, Expression of LCMVspecific antigens on hybridoma cells (4/4F7) producing LCMV-specific neutralizing antibodies staining with a rabbit anti-LCMV hyperimmune serum, followed by an FITC-labelled goat anti-rabbit (IgG) antibody. After subcloning, hybridomas were re-tested for virus in the culture supernatant for expression of virus antigen on the surface of the clones and for secretion of neutralizing antibodies $(c, d)$. The uninfected clone (c) did not produce LCMV-specific neutralizing antibodies. Neutralizing antibodies were found in the culture supernatant of the LCMV-infected clone $(d)$ after the supernatant had been inactivated. e, Lack of LCMV antigen expression on a representative cloned hybridoma producing anti-LCMV-NP-specific antibodies.

METHODS. $4 \times 10^{5}$ hybridoma cells were incubated with a rabbit antiLCMV-specific hyperimmune serum $\left(1: 10\right.$ dilution) for $45-60$ min at $4{ }^{\circ} \mathrm{C}$ and washed 3 times with PBS/0.05\% EDTA, followed by incubation with FITC-labelled goat anti-rabbit antibody (TAGO; 1: 50 dilution) for $30 \mathrm{~min}$ at $4{ }^{\circ} \mathrm{C}$. After 3 washes, cells were fixed with BSS/4\% paraformaldehyde for flow cytometric analysis. Viable cells were gated by a combination of forward light scatter and $90^{\circ}$ side scatter and were analysed on a FACSCAN (Becton Dickinson).

complex (MHC) class I molecules should render the specific LCMV-neutralizing B cells susceptible to lysis by specific cytotoxic $\mathrm{T}$ cells. Therefore, the LCMV-infected, neutralizing-antibodyproducing hybridomas were tested as target cells for LCMVspecific cytotoxic T cells in vitro. We found that LCMV-infected

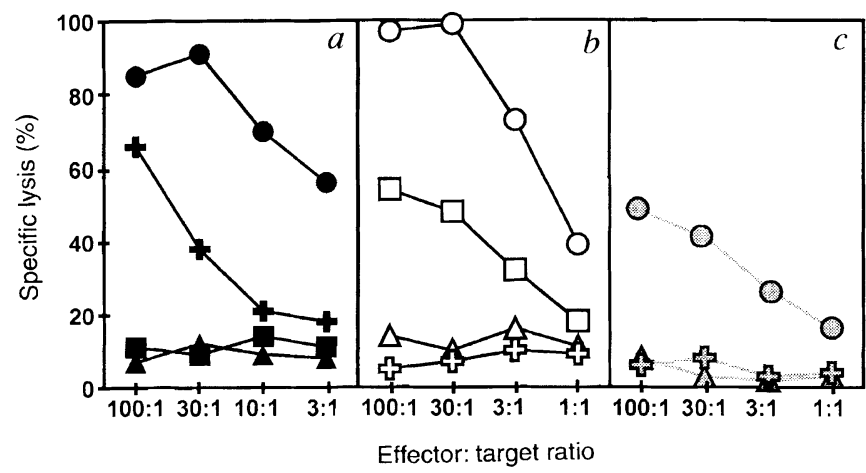

FIG. 3 LCMV infected hybridomas as target cells for LCMV-specific cytotoxic T cells. a, ${ }^{51}$ Chromium release assay using two LCMV-infected neutralizing antibody-secreting hybridomas (circles and crosses) and two uninfected NP-specific antibody-secreting hybridomas (squares and triangles) as target cells. Effector cells were spleen cells from a BALB/c mouse $\left(H-2^{d}\right)$ seven days after infection with LCMV-WE $10^{2}$ PFU. $b$, Uninfected NPspecific antibody-secreting hybridomas were either incubated for $48 \mathrm{~h}$ with LCMV, m.o.i 0.01 (triangles), or labelled with LCMV-specific peptide NP 118-126 (squares). Also, MHC-matched fibroblasts were either incubated with the NP 118-126 peptide (circles) or were used without further treatment as controls (crosses). c, Hybridoma (9/4A5) producing LCMVneutralizing antibody that was originally infected but was then rendered virus-free by subcloning, was incubated for $48 \mathrm{~h}$ with LCMV, m.o.i. 0.01, 1 or 100 (shaded crosses; data for 1 and 100 not shown), or labelled with LCMV-specific peptide NP 118-126 (circles), or used as target without any further treatment (triangles).

METHODS. Hybridomas used as target cells were incubated with $50 \mu \mathrm{Ci}$ of ${ }^{51} \mathrm{Cr}$ per ml overnight, were washed extensively and incubated at different effector to target ratios with effector spleen cells. Peptide labelling of the hybridomas was done for $2 \mathrm{~h}$ before the assay at a peptide concentration of $10^{-6} \mathrm{M}$. Fibroblasts were labelled with $200 \mu \mathrm{Ci}{ }^{51} \mathrm{Cr}$ per $\mathrm{ml}$ and peptide NP $118-126$ for $2 \mathrm{~h}$ before assaying. CTL activity was detected in a $6-\mathrm{h}{ }^{51} \mathrm{Cr}$ release assay. Spontaneous lysis was $<25 \%$. 
TABLE 1 Correlation of frequency and specificity of LCMV-specific hybridomas with CD8 ${ }^{+}$T-cell competence and time after LCMV infection

\begin{tabular}{|c|c|c|c|c|c|c|c|c|c|c|c|c|}
\hline \multirow{4}{*}{$\begin{array}{l}\text { Treatment of host* } \\
\text { (Days after infection) } \\
\text { d } 2 \\
\text { d } 2 \text {, anti-CD8 }\end{array}$} & \multirow{2}{*}{\multicolumn{2}{|c|}{$\begin{array}{l}\text { Hybridomas per fusion } \\
\text { in } 960 \text { wells* } \\
\text { (total number) } \%\end{array}$}} & \multirow{2}{*}{\multicolumn{2}{|c|}{$\begin{array}{l}\text { LCMV-infected } \\
\text { hybridoma cultures } \\
\text { (positive/total) } \%\end{array}$}} & \multicolumn{4}{|c|}{$\begin{array}{c}\text { Hybridomas secreting LCMV-specific } \\
\text { antibodies } \dagger \\
\text { (positive/total) } \%\end{array}$} & \multicolumn{4}{|c|}{$\begin{array}{l}\text { LCMV-producing hybridomas } \ddagger \\
\text { (positive/total) \% }\end{array}$} \\
\hline & & & & & \multicolumn{2}{|c|}{ Neutralizing } & \multicolumn{2}{|c|}{ NP-binding } & \multicolumn{2}{|c|}{ Neutralizing } & \multicolumn{2}{|c|}{ NP-binding } \\
\hline & (94) & 10 & $(13 / 94)$ & 14 & $(0 / 94)$ & 0 & $(0 / 94)$ & 0 & $(0 / 0)$ & - & $(0 / 0)$ & - \\
\hline & (56) & 6 & $(6 / 56)$ & 11 & $(0 / 56)$ & 0 & $(0 / 56)$ & & $(0 / 0)$ & - & (0/0) & - \\
\hline d 4 & (46) & 5 & $(10 / 46)$ & 22 & $(4 / 46)$ & $9 \S$ & $(7 / 46)$ & 15 & $(4 / 4)$ & 100 & $(0 / 7)$ & 0 \\
\hline d 4, anti-CD8 & (85) & 9 & $(31 / 85)$ & 37 & $(13 / 85)$ & $15^{\circ}$ & $(10 / 85)$ & 9 & $(11 / 13)$ & 85 & $(1 / 10)$ & 10 \\
\hline d 6 & (94) & 10 & (11/94) & 12 & $(3 / 94)$ & 3 & (18/94) & 19 & $(3 / 3)$ & 100 & $(0 / 18)$ & 0 \\
\hline d 6, anti-CD8 & (104) & 11 & (21/104) & 20 & $(17 / 104)$ & 16 & $(20 / 104)$ & 19 & $(17 / 17) \|$ & 100 & $(1 / 20)$ & 5 \\
\hline d 10 & (42) & 4 & $(3 / 42)$ & 7 & $(0 / 42)$ & 0 & $(8 / 42)$ & 19 & $(0 / 0)$ & - & $(0 / 8)$ & 0 \\
\hline d 10, anti-CD8 & (34) & 4 & $(5 / 34)$ & 15 & $(5 / 34)$ & 15 & $(6 / 34)$ & 18 & $(5 / 5) \|$ & 100 & $(0 / 6)$ & 0 \\
\hline d 25 & $(47)$ & 5 & $(3 / 47)$ & 7 & $(1 / 47)$ & 2 & $(13 / 47)$ & 28 & $(0 / 1)$ & 0 & $(0 / 13)$ & 0 \\
\hline d 25, anti-CD8 & (128) & $13 \pi$ & (18/128) & 14 & $(16 / 128)$ & 13 & $(18 / 128)$ & 14 & $(11 / 16)$ & 69 & $(0 / 18)$ & 0 \\
\hline
\end{tabular}

* Fusions of spleen cells were done on days 2, 4, 6, 10 and 25 after infection with $10^{6} \mathrm{PFU}$ of LCMV. Data are representative of one fusion for each day, using established protocols. Fusions were repeated independently at least twice with comparable results. Antibody assays determined by ELISA and neutralization and anti-CD8 treatment of mice have been described ${ }^{6}$.

$\dagger$ All hybridomas on day 2 (d 2) and d 4 secreted lgM. However, at later times most of the hybridomas produced lgG; $57 \%$ on d $6,74 \%$ on d 10 and $79 \%$ on $d 20$.

$\ddagger$ LCMV isolates from infected hybridomas were not variants that had escaped neutralization as they were all still neutralized by standard and the newly isolated neutralizing antibodies described here.

$\S$ Key data on percentages of hybridomas secreting neutralizing, versus those secreting non-neutralizing, antibodies in LCMV-infected normal or CD8 ${ }^{+} \mathrm{T}$ cell-depleted mice are boxed.

$\|$ Some of the hybridomas were initially probably not clonal. During further culturing and subcloning, some hybridomas were lost. Representations of some $\geqslant 3$ times subcloned, stable, homogeneous and independent hybridomas (from day 6 , anti-CD8 fusion: 13/8D2 IgM, titre: 2.5 at $1 \mu \mathrm{g} \mathrm{ml}{ }^{-1} ; 13 / 1 \mathrm{~A} 6 \mathrm{IgG}^{\mathrm{a} a}$, titre: 1.8; 13/3H12 IgG1, titre: 3.0, 4/4F7 IgG2a, titre: 5.4. From day 10, anti-CD8 fusion: 7/15A9 IgGb, titre: 8.4; 9/4A5 IgG2a, titre: 4.9; standard LCMVneutralizing antibody KL25: titre, 4.8) were studied in detail. Additional fusions using BALB/c and C57BL/6 mice yielding more than 2,000 primary hybridomas with about $10 \%$ cultures with anti-LCMV specificity confirmed these results.

I The relative increased number of hybridomas on day 25 in anti-CD8-treated mice reflects the known antigen persistence and continued stimulation at that time.

hybridomas were killed by specific $\mathrm{CD} 8^{+} \mathrm{T}$ cells, whereas hybridomas producing antibodies directed against LCMV-NP were not (Fig. $3 a$ ). The latter hybridomas preincubated with the immunodominant cytotoxic-T-cell peptide NP 188-126 for H-2 ${ }^{\text {d }}$ (refs 17, and the evidence from kinetic studies of neutralizing anti-LCMV antibody titres in mice suggested that neutralization-specific B cells were eliminated by LCMV-specific $\mathrm{CD}^{+} \mathrm{T}$ effector cells in vivo.

It could be argued that the difference in kinetics between the early appearance of NP-specific antibodies (days 6-8) compared with the later (days 15-25) appearance of neutralizing antibodies in the serum of $\mathrm{CD} 8^{+}$T-cell-depleted mice (Fig. 1) is not fully compatible with the proposed mechanism. The delay in neutralizingantibody kinetics, however, may be due to prolonged high titres of circulating virus caused by the absence of antiviral $\mathrm{CD} 8^{+} \mathrm{T}$ cells. Whether this virus exhaustively absorbs neutralizing antibodies as they appear in serum and renders them undetectable remains to be investigated: this might explain why neutralizing antibodies are detectable as soon as the virus titre drops in the blood of $\mathrm{CD}^{+} \mathrm{T}$ start to recover 8-10 days after depletion ${ }^{19}$.

It is possible that $\mathrm{CD}^{+}$or $\mathrm{CD} 4^{+} \mathrm{T}$ cells may destroy $\mathrm{B}$ cells that have taken up and presented antigen in association with class I or II MHC molecules ${ }^{20-22}$. For example, B cells transformed by Epstein-Barr virus (EBV) and exposed to non-infectious HBV surface (HBs) antigen are susceptible to lysis by HBs-specific HLA class I- and possibly class II-restricted CTLs in vitro ${ }^{10.23}$. It is protein antigens and the results described here with LCMV-NP suggest that this mechanism does not play a significant role in the regulation of antibody responses to non-infectious antigens in

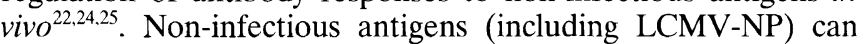
induce $\mathrm{CD}^{+} \mathrm{T}$-cell responses in vivo or in vitro ${ }^{26}$, but these conditions are not able to downregulate specific B-cell responses to the same antigens in vivo. This indicates that $\mathrm{B}$ cells must be 18) were efficiently lysed (Fig. $3 b$ ). These results with hybridomas cell-depleted LCMV-infected mice, when $\mathrm{CD} 8^{+} \mathrm{T}$-cell responses important that much of the earlier evidence with non-infectious

infected to become targets for 'suppressive' cytotoxic T cells and that this does not occur if non-infectious forms of antigens (even of the highly expressed LCMV-NP ${ }^{6}$ ) are taken up by specific B cells in vivo.

Our results suggest that during LCMV infection, B cells specific for the viral surface antigens can be selectively and productively infected by LCMV through their membrane-anchored neutralizingantibody receptor and are subsequently eliminated by virusspecific CTLs. In contrast, neutralizing-antibody-secreting hybridomas (and probably plasma cells) cannot any longer be infected because they lack the membrane-anchored surface immunoglobulin. It will be interesting to discover how and why B cells are able to support replication of non-cytopathic viruses, and how $B$ cells resist infection by cytopathic viruses, as the latter induce early neutralizing antibodies that are essential for host survival ${ }^{27,28}$.

An implication of our findings is that this mechanism might play a role in EBV infections ${ }^{29}$ and they could explain observations in $\mathrm{HBV}^{2}$ and $\mathrm{HIV}$ infections in humans, where non-neutralizing antibody responses also appear early and where the virusspecific neutralizing-antibody response has also been found to be strongly delayed. A highly specialized form of adaptation of host and virus may exist, in which some viruses 'use' immunological effector pathways to prevent early generation of protective neutralizing antibody responses, thereby permitting virus either to persist for a prolonged period or to establish a carrier state.

Received 11 April; accepted 3 July 1996.

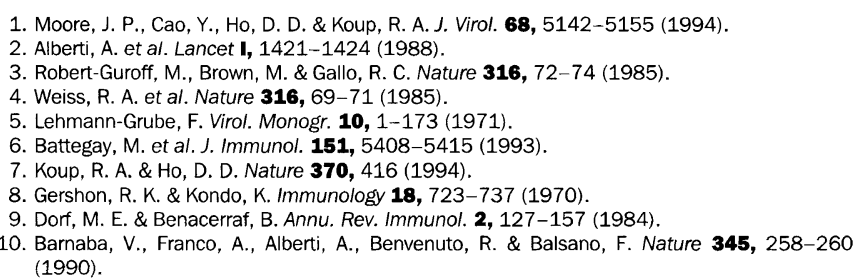


11. Buchmeier, M. J., Welsh, R. M., Dutko, F. J. \& Oldstone, M. B. A. Adv. Immunol. 30, 275-331 (1980).

12. Kägi, D. et al. Nature 369, 31-37 (1994)

13. Leist, T. P. Rüedi, E. \& Zinkernagel, R. M. J. Exp. Med. 167, 1749-1754 (1988).

14. Odermatt, B., Eppler, M., Leist, T. P., Hengartner, H. \& Zinkernagel, R. M. Proc. Natl Acad. Sci. USA 88, 8252-8256 (1991)

15. Borrow, P., Evans, C. F. \& Oldstone, M. B. A. J. Virol. 69, 1059-1070 (1995).

16. Bruns, M., Cihak, J., Müller, G. \& Lehmann-Grube, F. Virology 130, 247-251 (1983).

17. Whitton, J. L. et al. J. Virol. 63, 4303-4310 (1989).

18. Schulz, M. et al. Eur. J. Immunol. 19, 1657-1667 (1989).

19. Moskophidis, D., Cobbold, S. P., Waldmann, H. \& Lehmann-Grube, F. J. Virol. 61, 1867-1874 (1987).

20. Staerz, U. D., Karasuyama, H. \& Garner, A. M. Nature 329, 449-451 (1987).

21. Shinohara, N., Watanabe, M., Sachs, D. H. \& Hozumi, N. Nature 336, 481-484 (1988)

22. Raychaudhuri, S. \& Morrow, W. J. W. Immunol. Today 14, 344-348 (1993).

23. Hisatsune, T., Nishijima, K., Kohyama, M., Kato, H. \& Kaminogawa, S. J. Immunol. 154, 88-96 (1995)

24. Chesnut, R. W. Colon, S. M. \& Grey, H. M. J. Immunol. 129, 2382-2388 (1982)

25. Lanzavecchia, A. Annu. Rev. Immunal 8, 773-793 (1995).

26. Bachmann, M. F et al Eur. J Immunol 24, 2128-2236 (1994).

27. Mims, C. A. The Pathogenesis of Infectious Disease (Academic, London, 1987)

28. Gobet, R., Cerny, A., Rüedi, E., Hengartner, H. \& Zinkernagel, R. M. Exp. Cell Biol. 56, 175-180 (1988)

29. Henle, W. \& Henle, G. Cancer Res. 41, 4222-4225 (1981).

ACKNOWLEDGEMENTS. We thank E. Horvath and A. Althage for technical asistance, and K. Maloy, P. Klenermann, A. Gallimore S. Ehl, U. Kalinke, S. Oehen, M.v.d. Broek, A. Oxenius, D. Binder and P. Aichele for discussion. This work was supported by grants from the Swiss NSF and Fondation P. Aichele for discussion. This wort
Jeantet and the Kanton Zürich.

CORRESPONDENCE and requests for materials should be addressed to O.P.

\section{Deoxycytidyl transferase activity of yeast REV1 protein}

\author{
John R. Nelson*, Christopher W. Lawrence* \\ \& David C. Hinkle $\dagger$
}

Departments of * Biophysics and † Biology, University of Rochester, Rochester, New York 14642-8408, USA

MUTAGENESIS induced by DNA damage in Saccharomyces cerevisiae requires the products of the $R E V 1, R E V 3$ and $R E V 7$ genes ${ }^{1}$. The Rev3 and Rev7 proteins are subunits of DNA polymerase-zeta ${ }^{2}$ (Pol- $\zeta$ ), an enzyme whose sole function appears to be translesion synthesis $^{3}$. Rev1 protein has weak homology with UmuC protein ${ }^{4}$, which facilitates translesion synthesis in Escherichia coli by an unknown mechanism. We show here that Rev1 protein has a deoxycytidyl transferase activity which transfers a dCMP residue from dCTP to the $3^{\prime}$ end of a DNA primer in a template-dependent reaction. Efficient transfer occurred opposite a template abasic site, but $\sim 20 \%$ transfer also occurred opposite a template guanine and $\sim 10 \%$ opposite adenine or uracil; $\leq 1 \%$ was seen opposite thymine or cytosine. Insertion of cytosine opposite an abasic site produced a terminus that was extended efficiently by

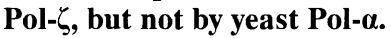

The deoxycytidyl transferase activity was discovered when testing the ability of Rev1 protein to enhance bypass of a template lesion by DNA polymerase $\zeta$, using a glutathione- $S$-transferase (GST)-Rev1 fusion overexpressed in yeast and purified to nearhomogeneity by affinity chromatography on glutathione-Sepharose (Fig. 1). The transferase activity was highly specific for dCTP and transferred a dCMP residue to the $3^{\prime}$ end of a DNA primer in a template-dependent reaction. Transferase activity was proportional to enzyme concentration and the kinetics were linear up to at least $10 \mathrm{~min}$, or until $\sim 75 \%$ of the primers had been extended. Primers were not extended in the absence of a template, and the enzyme could not use ribonucleoside triphosphates. With the primer-template oligonucleotide pairs shown (Fig. 2), no primer extension was observed when the first template nucleotide was a $\mathrm{T}$ or a $\mathrm{C}$, but two $\mathrm{C}$ residues were added to the primer paired with a template containing two adjacent $\mathrm{G}$ residues. These $\mathrm{C}$ residues were added in a processive reaction as almost all of the extended primers contained two $C$ residues, even under conditions where only a small fraction of the primer molecules were extended. A single $\mathrm{C}$ residue was also added opposite a template $\mathrm{A}$ but not a second residue, even though the template oligonucleotide contained two adjacent $\mathrm{A}$ residues. $\mathrm{A}$ single $\mathrm{C}$ residue was also added to oligo $(\mathrm{dT})_{25} \cdot \operatorname{poly}(\mathrm{dA})$.

Previous experiments in vivo, demonstrating a marked preference for dCMP insertion opposite an abasic lesion in yeast $t^{5}$, prompted us to test whether the Rev1 transferase could insert a dCMP residue opposite this lesion. We constructed a template oligonucleotide with a specific dUMP residue and then treated the DNA with uracil- $N$-glycosylase to convert it to an abasic site. The transferase inserted dCMP opposite this abasic site about fivefold more efficiently than it did opposite a template G. Surprisingly, although the enzyme is unable to use a template $\mathrm{T}, \mathrm{dCMP}$ was inserted with low efficiency opposite uracil, used in a control template. This was not a consequence of Rev1 containing uracil- $N$-glycosylase activity, because treatment of the template with Rev1 did not result in the alkali cleavability characteristic of an abasic site. Normalized to insertion opposite the abasic site, insertion efficiency opposite $\mathrm{G}$ was $20 \%$, opposite $\mathrm{A}$ and $\mathrm{U}$ was $10 \%$, and opposite $\mathrm{C}$ and $\mathrm{T}$ was $1 \%$ or less. Interestingly, only a single dCMP residue was added to the primer when the template contained two adjacent abasic sites, and the same true was when the abasic site was followed by guanine. In contrast, two dCMP nucleotides were added when a template uracil was followed by guanine.

The efficiency of insertion opposite a template abasic site suggests that Rev1 activity may assist in the first step in the bypass of these lesions, the insertion of a nucleotide opposite the lesion. We therefore examined the ability of Pol- $\zeta$ and yeast Pol- $\alpha$ to complete the bypass replication by extending the resulting $3^{\prime}$ terminus (Fig. 3). In the absence of Rev1, Pol- $\zeta$ was capable of both inserting a nucleotide opposite the abasic site and further

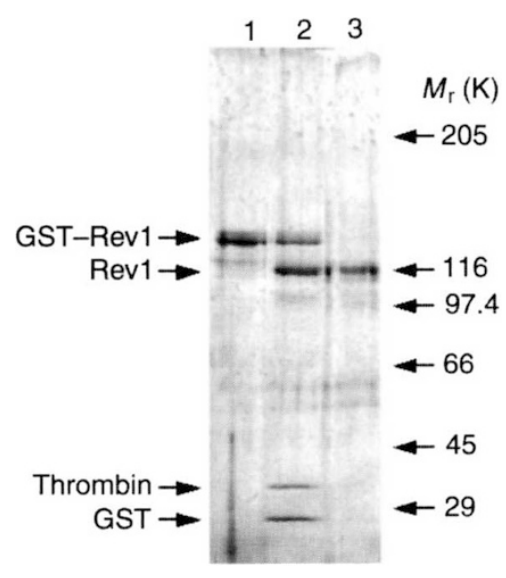

FIG. 1 SDS-polyacrylamide gel electrophoresis analysis of purified Rev1 proteins. Lane 1, eluate from the glutathione-Sepharose column, showing the $\sim 140 \mathrm{~K}$ GST-Rev1 fusion protein. Lane 2, products from cleavage at the thrombin-sensitive site at the GST-Rev1 fusion jucntion. Lane 3, the Rev1 cleavage product further purified by fractionation on a glycerol gradient.

METHODS. A GST-Rev1 fusion protein was overexpressed in yeast containing the plasmid pGST-REV1, constructed by inserting a 3.5-kb DNA fragment containing REV1 between the BamHl and Pstl cloning sites of pGST, and purified by affinity chromatography on glutatione-Sepharose as described for the purification of a GST-Rev3 protein ${ }^{2}$. About $300 \mu \mathrm{g}$ GSTRev1 was obtained from $5 \mathrm{~g}$ of yeast paste. A portion $(14 \mu \mathrm{g})$ of the glutathione-Sepharose fraction was incubated for $15 \mathrm{~h}$ at $4{ }^{\circ} \mathrm{C}$ with $3 \mu \mathrm{g}$ of thrombin and sedimented on a $10-30 \%$ glycerol gradient containing $0.5 \mathrm{M} \mathrm{NaCl}$. Electrophoresis was on a $5-15 \%$ polyacrylamide gel and the gel was stained with silver. 